\title{
\begin{tabular}{l|l|l}
\hline Journal of Innovation, Evaluation and Learning Development \\
\hline
\end{tabular}
}

\section{Efektivitas Penggunaan Buku Ajar Sastra Lisan Suku Mbojo Berorientasi pada Model CIRC untuk Matakuliah Apresiasi Sastra}

\author{
Taufik $^{1}$, M. Nur Imansyah ${ }^{2}$, Eka Yulianti ${ }^{3}$ \\ 1,3Program Studi Pendidikan Bahasa dan Sastra Indonesia, STKIP Yapis Dompu \\ ${ }^{2}$ Program studi Pendidikan Teknologi Informasi, STKIP Yapis Dompu \\ E-mail: taufikbima25@gmail.com
}

Article History: Received: 2021-10-12 || Revised: 2021-11-27 || Published: 2021-12-30

Sejarah Artikel : Diterima: 2021-10-12 || Direvisi: 2021-11-27 || Dipublikasi: 2021-12-30

\begin{abstract}
Research has been carried out with the title of the effectiveness of using Mbojo tribal oral literature textbooks for literary appreciation courses. The purpose of this study is to assess the effectiveness of a textbook that demonstrates local culture that focuses on a cooperative learning model. The method used in this research is the development model of Thiagarajan known as Four-D Models (4-D). The results of the feasibility assessment by the content validator are $80.72 \%$ (very feasible) and the learning media validator is $91.51 \%$ (very feasible). The effectiveness test shows that the textbook is effective in improving learning outcomes compared to other textbooks.
\end{abstract}

Keywords: Effectiveness, Textbooks, Oral Literature, CIRC Models.

\begin{abstract}
Abstrak
Telah dilakukan penelitian dengan judul efektivitas penggunaan buku ajar sastra lisan suku Mbojo untuk matakuliah apresiasi sastra. Tujuan penelitian ini yakni untuk menilai keefektivan sebuah buku ajar yang memandukan budaya lokal yang berfokus pada sebuah model pembelajaran yang kooperatif. Metode yang digunakan pada penelian ini adalah model pengembangan dari Thiagarajan yang dikenal dengan Four-D Models (4-D). Hasil penilaian kelayakan oleh validator isi sebesar $80.72 \%$ (sangatlayak) dan validator media pembelajaran sebesar $91.51 \%$ (sangat layak). Uji efektivitas menunjukkan bahwa buku ajar tersebut efektif meningkatkan hasil belajar dibanding dengan buku ajar lain.
\end{abstract}

Kata kunci: Efektivitas, Buku Ajar, Sastra Lisan, Model CIRC.

\section{PENDAHULUAN}

Pembelajaran merupakan peran serta usaha dari dosen yang dilakukan secara sadar dalam upaya membantu mahasiswa dalam kegiatan belajar mengajar agar terciptanya aktivitas pembelajaran yang aktif, efektif dan efisien. Pembelajaran dikatakan berhasil apabila pembelajaran tersebut dapat menumbuhkembangkan potensi yang dimiliki mahasiswa, sehingga dapat memperoleh manfaat secara langsung bagi pengembangan diri. Dengan demikian, untuk mencapai hal tersebut, maka kegiatan pembelajaran memerlukan prasarana yang memadai. Artinya, agar memperoleh hasil maksimal, maka kadar interaksi itu harus tinggi. Menyikapi uraian tersebut, hendaknya proses pembelajaran di kelas dikelola dengan baik, secara kualitas maupun kuantitas, mengingat persaingan yang terjadi pada abad 21 ini menumbuhkan kompetisi antar bangsa di dunia, sehingga menuntut adanya pengembangan kualitas sumber daya manusia (Rusman, 2012). Optimalisasi dari variabel tersebut dapat memberikan kontribusi positif bagi dosen dalam menyelesaikan tugas akademik dengan hasil belajar yang memuaskan. Selain itu, kondisi atau situasi yang memungkinkan terjadinya proses belajar harus dirancang dan dipertimbangkan terlebih dahulu oleh perancang atau tenaga pendidik dengan memperhatikan berbagai prinsip pembelajaran yang telah diuji keunggulannya.

Dalam proses pembelajaran ada beberapa komponen yang saling berkaitan. Komponen-komponen tersebut adalah tujuan, bahan ajar, kegiatan belajar mengajar, metode, alat, sumber belajar dan evaluasi. Komponen-komponen tersebut merupakan pendukung yang dapat membantu dosen 
dalam proses pembelajaran sehingga tujuan pembelajaran dapat tercapai secara efektif dan efisien. Majid (2005:174) menyatakan bahwa "buku ajar adalah segala bentuk bahan yang digunakan untuk membantu dosen dalam melaksanakan kegiatan belajar mengajar di kelas". Keefektifan hasil belajar seseorang dipengaruhi oleh berbagai faktor. Salah satunya dengan ketersediaanya sebuah buku ajar yang memandukan budaya lokal yang berfokus pada sebuah model pembelajaran yang kooperatif. Oleh karena itu, sangat diperluakan sebuah model yang mampu memenuhi kekurangan tersebut. Salahsatunya dengan menggunakan model CIRC yang memberikan kemudahan bagi mahasiswa untuk mempelajarinya, sehingga hasil belajar akan lebih baik.

Model Pembelajaran CIRC adalah salah satu model pembelajaran kooperatif terpadu membaca dan menulis, dimana mahasiswa di bagi menjadi beberapa kelompok untuk meningkatkan kemampuan pemahaman dalam membaca, menulis, memahami kosakata, dan seni berbahasa. Menurut Uno dan Muhamad (2011), model CIRC merupakan salah satu tipe model pembelajaran kooperatif yang merupakan komposisi terpadu membaca dan menulis secara kooperatif (kelompok), yaitu membaca materi yang diajarkan dari berbagai sumber dan selanjutnya menuliskannya ke dalam bentuk tulisan yang dilakukan secara kooperatif. Buku ajar yang dikembangkan dengan model CIRC akan menjadi perangkat pembelajaran yang memungkinkan mahasiswa melakukan aktivitas belajar dengan maksimal. Buku ajar tersebut dimaksudkan untuk membantu dosen dalam meningkatkan efektivitas dan efisiensi kegiatan belajar mengajar di kelas. Dengan demikian penelitian ini untuk menguji keefektivan dari buku ajar sastra lisan suku Mbojo yang berorientasi pada model CIRC untuk matakuliah Apresiasi sastra.

\section{METODE PENELITIAN}

Model pengembangan yang akan digunakan untuk mengembangkan perangkat pembelajaran dalam penelitian ini adalah model Thiagarajan (dalam Taufik, Erwin, 2020) yang dikenal dengan Four-D Models. Alasan menggunakan model ini karena lebih sederhana, tidak rumit, sistematis, lebih spesifik serta mudah diikuti langkah-langkah pengembangannya. Tahapan pengembangan buku ajar tersebut dijabarkan ke dalam 4 langkah yaitu: (1) tahap pendefinisian (Define), (2) tahap perancangan (Design), (3) tahap pengembangan (Develop), (4) tahap penyebarluasan hasil pengembangan (Disseminate). Alur pengembangan yang dilakukan dalam penelitian ini, sampai pada tahap 3 (tahap pengembangan) saja dan dilakukan uji coba terbatas di STKIP Yapis Dompu.

Instrumen uji efektifitas berupa instrumen perlakuan dan instrumen pengukuran. Instrumen pengukuran berupa soal, butir soal yang telah divalidasi, reliabilitas, dayabeda dan tingkat kesukaran. Efektifitas bahan ajar hasil pengembangan dilihat dari hasil belajar mahasiswa (postes) setelah mahasiswa menyelesaikan seluruh kegiatan pembelajaran menggunakan bahan ajar tersebut. Indikator yang digunakan dalam uji efektifitas adalah rerata nilai postes, pencapaian nilai Kriteria Ketuntasan Minimal (KKM), yaitu siswa yang mencapai KKM minimal 80\% dan uji t menggunakan independent sampel t test terhadap hasil postes kelas eksperimen dan kelas kontrol. Buku ajar hasil pengembangan dikatakan efektif jika rerata nilai postes kelas yang menggunakan bahan ajar hasil pengembangan lebih tinggi dibandingkan dengan kelas yang menggunakan Bahan ajar lain yang ada disekolah (hasil uji $t<0.05$ ). Respon siswa berupa penilaian, komentar, maupun saran setelah dibelajarkan dengan menggunakan bahan ajar hasil pengembangan. Respon mahasiswa digunakan sebagai acuan untuk mengetahui persepsi siswa terhadap bahan ajar hasil pengembangan.

\section{HASIL DAN PEMBAHASAN}

Buku Ajar ajar hasil pengembangan berupa buku ajar sastra lisan suku Mbojo berorientasi pada model CIRC untuk matakuliah apresiasi sastra dalam bentuk cetak. Sistematika buku ajar hasil pengembangan terdiri dari pra pendahuluan, pendahuluan, kegiatan pembelajaran, uji kompetensi, dan daftar pustaka. Bahan ajar hasil pengembangan terdiri dari tiga kegiatan pembelajaran, dimana setiap kegiatan pembelajaran berisi tujuan dan rencana pembelajaran. Setiap kegiatan pembelajaran dilengkapi dengan materi-materi tentang sastra lisan suku mbojo (kapatu dan mantra Mbojo) yang bertujuan untuk menambah pengetahuan dan wawasan mahasiswa yang ada di STKIP Yapis Dompu. Data yang diperoleh dalam penelitian ini berupa uji kelayakan, efektivitas serta respon mahasiswa terhadap bahan ajar hasil pengembangan. Hasil dan pembahasan penelitian akan disajikan berikut ini: 


\section{A. Hasil Kelayakan Buku Ajar}

Hasil Uji kelayakan terhadap perangkat Pembelajaran Buku ajar yang dikembangkan disajikan dalam tabel berikut ini

Tabel 1. Hasil validasi kelayakan Buku Ajar Sastra Lisan Suku Mbojo

\begin{tabular}{llcccc}
\hline No & Validator & Buku Dosen & Buku Mahasiswa & Rata-Rata (\%) & Kriteria \\
\hline $\mathbf{1}$ & Bahasa & 80.67 & 90.67 & 85.67 & Sangat Layak \\
\hline $\mathbf{2}$ & Isi / Materi & 80.76 & 92.34 & 86.55 & Sangat Layak \\
\hline & Rata-Rata & $\mathbf{8 0 . 7 2}$ & $\mathbf{9 1 . 5 1}$ & $\mathbf{8 6 . 1 1}$ & Sangat Layak \\
\hline
\end{tabular}

Berdasarkan data pada Tabel 1 rata-rata hasil dari validasi kelayakan buku ajar sastra lisan suku Mbojo oleh beberapa ahli (Validator) isi/materi dan ahli media pembelajaran terhadap buku ajar berupa buku Dosen adalah sebesar 80, 72\% dan buku siswa sebesar 91,51\% dengan kategori sangat layak. Kriteria penilaian tersebut meliputi kelayakan bahasa dan kelayakan isi/materi. Hasil validasi tersebut dapat dikatakan bahwa secara umum bahan ajar hasil pengembangan yang berupa buku Dosen dan buku mahasiswa sangat layak untuk digunakan dalam kegiatan pembelajaran. Hal ini dikarenakan dari segi isi/materi bahan ajar menyajikan konten yang sesuai dengan kompetensi dasar yang terdapat dalam kurikulum.

\section{B. Hasil Uji Keterbacaan Buku Ajar}

Hasil penilaian uji keterbacaan meliputi aspek kelayakan isi, kebahasaan, sajian, dan Soal Tes. Uji keterbacaan bahan ajar dilakukan oleh 2 orang dosen dan 6 orang mahasiswa Semester V dengan komposisi 2 orang siswa berkemampuan tinggi, 2 orang mahasiswa berkemampuan sedang dan 2 orang mahasiswa berkemampuan rendah. Hasil uji keterbacaan bahan ajar disajikan pada Tabel berikut ini:

Tabel 2. Hasil Validasi Uji Keterbacaan Buku Ajar

\begin{tabular}{llcccc}
\hline No & Aspek yang Diamati & $\begin{array}{c}\text { Buku } \\
\text { Dosen }\end{array}$ & $\begin{array}{c}\text { Buku } \\
\text { Mahasiswa }\end{array}$ & $\begin{array}{c}\text { Rata-Rata } \\
\text { (\%) }\end{array}$ & Kriteria \\
\hline 1 & Tampilan/ Sajian & 92.67 & 78.91 & 85.79 & Sangat Layak \\
\hline 2 & Isi/ Komponen Buku ajar & 90.18 & 87.05 & 88.62 & Sangat Layak \\
\hline 3 & Bahasa & 87.66 & 90.97 & 89.32 & Sangat Layak \\
\hline 4 & Soal Tes & 85.76 & 93.24 & 89.50 & Sangat Layak \\
\hline & Rata-Rata & $\mathbf{8 9 . 0 7}$ & $\mathbf{8 7 . 5 4}$ & $\mathbf{8 8 . 3 1}$ & Sangat Layak \\
\hline
\end{tabular}

Berdasarkan Tabel 2 diketahui bahwa hasil uji keterbacaan pengguna bahan ajar hasil pengembangan baik yang dilakukan oleh Dosen maupun mahasiswa menunjukkan rata-rata nilai sebesar $88.31 \%$ dengan kategori sangat layak. Kelayakan buku ajar tersebut dikarenakan komponen-komponen yang terdapat dalam bahan ajar disajikan secara sistematis. Materi yang disampaikan diuraikan secara singkat dan jelas, sesuai dengan kompetensi dasar dalam kurikulum Perguruan Tinggi. Aspek tampilan/sajian, bahan ajar menyajikan materi yang didukung dengan contoh soal yang aplikatif sehingga mendorong mahasiswa untuk mempelajarinya lebih lanjut. Sajian pendahuluan yang interaktif merangsang rasa ingin tahu mahasiswa. Penggunaan bahasa yang komunikatif, dan sesuai dengan kaidah bahasa Indonesia yang baik dan benar memberikan kemudahan mahasiswa dalam memahami isi materi. Tampilan cover yang sangat menarik, pemilihan jenis huruf dan ukuran yang sesuai serta ilustrasi gambar yang relevan dengan materi sastra lisan suku Mbojo akan menimbulkan rasa ketertarikan yang sangat tinggi bagi pengguna untuk membacanya.

\section{Uji Efektivitas Buku Ajar}

Uji efektifitas Buku ajar hasil pengembangan diukur dari hasil belajar dan respon mahasiswa setelah menggunakan buku ajar dalam pembelajaran. Hasil belajar tersebut dibandingkan dengan hasil belajar dari mahasiswa yang diajarkan dengan buku ajar lain (kelas kontrol). Hasil belajar mahasiswa berupa nilai postes dari kelas eksperimen maupun kelas kontrol disajikan dalam Tabel 3. 
Tabel 3. Hasil Perolehan Nilai Postes dan Pencapaian KKM Kelas Eksperimen dan Kelas Kontrol

\begin{tabular}{llcc}
\hline No & Uji Lapangan terbatas & Rata-Rata Nilai Postes & Pencapaian KKM (\%) \\
\hline 1 & Kelas Control & 68.46 & $60 \%$ \\
\hline 2 & Kelas Eksperimen & 75.68 & $88 \%$ \\
\hline
\end{tabular}

Hasil uji efektivitas buku ajar sastra lisan suku Mbojo yang disajikan pada Tabel 3. Didapati bahwa rata-rata nilai postes dan pencapaian KKM kelas eksperimen lebih tinggi dibandingkan dengan kelas kontrol. Hasil analisis uji independent sampel t test didapatkan nilai signifikansi (2-tailed) sebesar 0,012<0,05 yang berarti bahwa ada perbedaan yang signifikan antara kelas eksperimen dan kelas control, setelah kegiatan pembelajaran, mahasiswa memberikan persepsi terhadap buku ajar hasil pengembangan yang digunakan. Persepsi mahasiswa terhadap buku ajar hasil pengembangan disajikan dalam Tabel 4.

Tabel 4. Hasil Respon Mahasiswa Terhadap Bahan Ajar Hasil Pengembangan

\begin{tabular}{clcc}
\hline No & Aspek yang Diamati & Rata-Rata Hasil Penilaian & Kriteria \\
\hline 1 & Tampilan/ Sajian & 86.67 & Sangat Layak \\
\hline 2 & Isi/ Komponen Buku ajar & 86.86 & Sangat Layak \\
\hline 3 & Bahasa & 90.24 & Sangat Layak \\
\hline 4 & Soal Tes & 86.32 & Sangat Layak \\
\hline & Rerata & $\mathbf{8 7 . 5 2}$ & Sangat Layak \\
\hline
\end{tabular}

Tabel 4 menunjukkan bahwa bahan ajar hasil pengembangan sangat baik. mahasiswa memberikan respon dari segi isi/komponennya sangat baik, sajiannya sangat menarik, bahasanya sangat mudah, dan soal tesnya yang sangat menarik. Oleh karena itu, mahasiswa sangat tertarik untuk menggunakannya.

\section{SIMPULAN DAN SARAN}

\section{A. Simpulan}

Berdasarkan hasil penelitian yang telah dilakukan, maka dapat disimpulkan bahwa buku ajar sastra lisan suku mbojo yang berorientasi pada model Cooperative Integrated Reading and Composition (CIRC) hasil pengembangan terbukti sangat efektif dalam meningkatkan hasil pembelajaran, hal tersebut dibuktikan dengan hasil belajar mahasiswa yang lebih tinggi dibandingkan dengan mahasiswa yang menggunakan bahan ajar lain, dan secara umum mahasiswa dapat memberikan persepsi positif terhadap buku ajar hasil pengembangan yang ditunjukkan dengan ketertarikan dan kemudahan mahasiswa dalam membaca dan menggunakannya.

\section{B. Saran}

Penelitian ini dapat dimanfaatkan sebagai tambahan pengetahuan dalam menambah wawasan tentang penggunaan buku ajar yang berorientasi pada model pembelajaran Cooperative Integrated Reading and Composition (CIRC) pada Mata Kuliah Apresiasi Sastra dan Hasil penelitian ini dapat dijadikan sebagai bahan referensi dalam pembelajaran kedepanya.

\section{DAFTAR RUJUKAN}

Epina, H. (2018). Pengaruh Penggunaan Model Cooperative Learning Tipe Cooperative Integrated Reading and Composition Terhadap Peningkatan Pemahaman Konsep Peserta Didik. Jurnal Pendidikan dan Pembelajaran EDUCARE, 16(2), 1-80.

Madjid, Abdul. (2005). Perencanaan Pengajaran. Bandung: PT Remaja RosdaKarya

Machali, I. (1970). Kebijakan Perubahan Kurikulum 2013 dalam Menyongsong Indonesia Emas Tahun 2045. Jurnal Pendidikan Islam, 3(1), 71. https://doi.org/10.14421/jpi.2014.31.71-94

Prasetya, Y. (2017). Pengembangan Buku Penunjang. Jurnal Pendidikan, 2(6), 751-755. 
Taufik, Erwin, \& Husnul Khatimah. (2020). Pengembangan Perangkat Pembelajaran Model CIRC pada Mata Kuliah Apresiasi Sastra "Mantra Mbojo" untuk Melatih Kemampuan Berpikir Kreatif Mahasiswa. JIIP - Jurnal Ilmiah Ilmu Pendidikan,3(3), 635-641. Retrieved from http://jiip.stkipyapisdompu.ac.id/jiip/index.php/JIIP/article/view/171

Taufik, Erwin, \& Husnul Khatimah. (2020). Model Pembelajaran CIRC pada Mata Kuliah Apresiasi Sastra "Mantra Mbojo" untuk Meningkatkan Kreativitas Mahasiswa. Ainara Journal (Jurnal Penelitian Dan PKM Bidang Ilmu Pendidikan), 1(2), 62-70. https://doi.org/10.1234567/ainarajournal.v1i2.15

Taufik. (2020). Mantra Mbojo (Sebagai Bahan Ajar pada Mata Kuliah Apresiasi Sastra) (E. Yulianti (ed.); 1st ed.). Nathan Indonesia.

Taufik, T., Imansyah, M. N., \& Yulianti, E. (2021). Pengembangan Buku Ajar Apresiasi Sastra Berbasis Sastra Lisan Suku Mbojo Berorientasi pada Model CIRC untuk Meningkatkan Kompetensi Mahasiswa. JIIP - Jurnal Ilmiah Ilmu Pendidikan, 4(6), 478-483. https://doi.org/10.54371/jiip.v4i6.285

Uno, H, Nurdin, M. (2011). “Belajar dengan Pendekatan PAILKEM”. Jakarta: Bumi Aksara. 